\title{
Decline in the pregnancy rate of Baltic grey seal females during the 2000s
}

\author{
Kaarina Kauhala ${ }^{1, \star}$, Markus P. Ahola ${ }^{1}$ \& Mervi Kunnasranta ${ }^{2}$ \\ 1) Finnish Game and Fisheries Research Institute, Itäinen Pitkäkatu 3 A, Fl-20520 Turku, Finland \\ ( ${ }^{*}$ corresponding author's e-mail: kaarina.kauhala@rktl.fi) \\ 2) University of Eastern Finland, Department of Biology, P.O. Box 111, Fl-80101 Joensuu, Finland
}

Received 18 June 2013, final version received 22 Oct. 2013, accepted 22 Nov. 2013

Kauhala, K., Ahola, M. P. \& Kunnasranta, M. 2014: Decline in the pregnancy rate of Baltic grey seal females during the 2000s. - Ann. Zool. Fennici 51: 313-324.

During the period 2000-2012 we witnessed a general increase in the Baltic grey seal (Halichoerus grypus) population size. Population growth has, however, ceased in the northern sea areas. The accompanying changes to age structure during this time suggest a reduced female pregnancy rate. In this study, we used hunted individuals to examine the ovulation and pregnancy rates of seals from different age classes and years. We examined the presence of corpus luteum, corpus albicans and placental scars from seals killed before the implantation period and fetuses after the implantation period. The pregnancy rate derived from the presence of corpus albicans or placental scars in the pre-implantation period was similar to that based on fetuses. Thirty-three percent of females ovulated at the age of 3 years, $81 \%$ at the age of 4 years and $99 \%$ thereafter. The pregnancy rate was lower among 4-5-year-old females (0.54-0.56) than among 6-24-year-old females $(0.77-0.86)$, being highest in 7-11-year-old females. The pregnancy rate of 6-24-year-old females decreased from 0.89 in 2000-2004 to 0.66 in 2005-2011 and correlated negatively with population size. The decreased pregnancy rate suggests that grey seal numbers in the northern part of the Baltic Sea may be today close to the carrying capacity of the environment.

\section{Introduction}

According to estimates there had been about 100000 Baltic grey seals (Halichoerus grypus) at the beginning of the 20th century but thereafter seal numbers declined and were lowest (about 2000-3000) in the 1970s (Jensen et al. 1969, Almkvist 1978, Bergman \& Olsson 1986, Kokko et al. 1997, Bergman 1999, Harding \& Härkönen 1999, Harding et al. 2007). One reason behind this dramatic decline was environmental pollution by organochlorines in the 1960s and 1970s, which likely caused severe reproductive disturbances (Bergman \& Olsson 1986, Bergman 1999, Harding \& Härkönen 1999, Bäcklin et al. 2003, Nyman et al. 2003). Due to decreased levels of environmental pollution in the Baltic Sea during recent decades (Routti 2009), reproductive health of seals has gradually improved and in the 2000s, virtually no reproductive disturbances have been observed (Bäcklin et al. 2011, 2013a, Roos et al. 2012). Accordingly, Baltic grey seal numbers have increased since the 1980s, and in 2012 the number of grey seals 


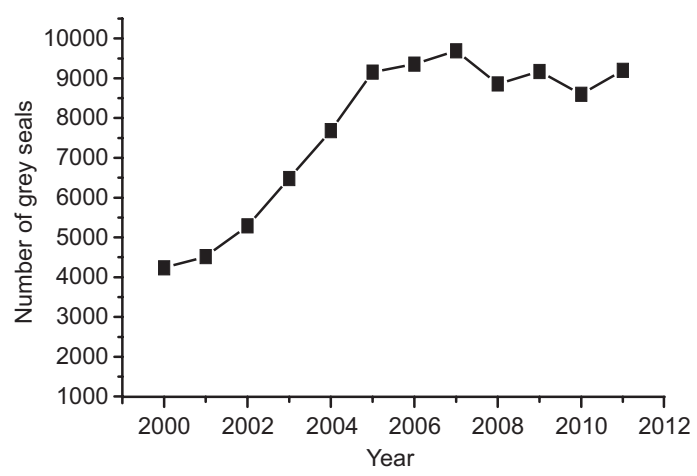

Fig. 1. Numbers of grey seals seen during aerial surveys in late May-early June in the Finnish sea area (Ahola 2014). Values were smoothed with three-year moving averages because of stochastic variation in the numbers of seals seen during aerial surveys.

seen in aerial surveys was about 10000 in the Finnish sea area and 28000 in the entire Baltic Sea (Ahola 2014).

The number of counted grey seals in the Finnish sea area increased until the mid-2000s but has fluctuated thereafter (Fig. 1). Furthermore, the demographic structure of the population changed and the mortality rate of especially females under 10 years old increased from the early to the late 2000s (Kauhala et al. 2012). The ceased population growth and the increased mortality rate may indicate that seal numbers in the northernmost areas of the Baltic Sea are approaching the carrying capacity of the environment. If this is the case, we can expect a decrease in the pregnancy rate during the 2000s (Begon et al. 1986, Harding et al. 2007, Svensson et al. 2011). It is important to know whether the population is close to carrying capacity when planning seal population management: the number of seals that can be hunted annually depends on the status of the population. Such information may also help to solve the seal-fishery conflict, which has arisen in Finland due to increased seal numbers: if the population has already reached its carrying capacity, more seals can be hunted and damage to coastal fisheries diminishes.

The grey seal is a seasonal and synchronized breeder giving birth to one pup in February or March in the Baltic Sea (Boyd et al. 1999). The pup is born on drift ice or on land, if there is no suitable ice available. The lactation period lasts almost three weeks. Seals have a postpartum estrus and spontaneous ovulation: females ovulate and mate at the end of the lactation period, 12-17 days after parturition (Atkinson 1997, Boyd et al. 1999). After fertilization there is a period of about 3.5 months when the blastocyst may grow slowly but remains unattached in the lumen of the uterus (Atkinson 1997). Implantation in Baltic grey seals takes place usually in July but sometimes not before early August (Bäcklin et al. 2011). The presence of fetuses after the implantation period (i.e. from early August onwards) can thus be used to calculate the pregnancy rate of a female seal population in the present year.

Corpus luteum (CL) is formed within 24 hours after ovulation and secretes progesterone which, with placental gonadotrophins, maintains pregnancy (Boyd et al. 1999). CL rapidly atrophies after parturition and changes to corpus albicans (CA; Boyd 1983, 1984a). Both the presence of $\mathrm{CA}$ and the remains of placental scars, which can often be seen in the uterus after parturition, indicate that the female gave birth in the present year, i.e. was pregnant the previous autumn (Boyd 1984a, 1985).

The reproductive capacity of a seal population is closely linked to population density in relation to the carrying capacity of the environment (e.g. Atkinson 1997), and is therefore essential information to proper management evaluations. The aim of the present study was to use hunted animals from the years 2000-2012 to evaluate the yearly pregnancy rate of Baltic grey seal females of different age groups from the presence of corpus albicans and placental scars before the implantation period, and from the presence of fetuses after the implantation period. We also aimed to estimate the ovulation rate of females from the presence of corpus luteum. We predicted that the pregnancy rate decreased during the 2000s, because growth rate declined and demographic structure of the population changed in the northern sea areas (Kauhala et al. 2012).

\section{Methods}

Samples of grey seals were collected from hunters and occasionally from fishermen's by-catch 
between 2000 and 2012 from the Finnish sea area including Åland: Bothnian Bay (ICES subdivision area 31), Bothnian Sea and the Quark (ICES SD 30), SW archipelago (ICES SD 29) and the Gulf of Finland (ICES SD 32; Fig. 2). Annually, several hundreds of grey seals are hunted in Finland during the hunting season from 16 April to 31 December (16 April-31 January in Åland). We received 575 samples of females, which were at least two years old. Younger females were excluded from the data since they are likely to be non-fertile (Boyd 1985).

Samples of each female seal included at least the uterus, ovaries and the lower jaw. Seal species was confirmed from the lower jaw. Age determination was done by counting incremental lines in the cementum from transversal sections of lower canine teeth (e.g. Mansfield 1991).

The uterus was first checked for the presence of occlusions or stenoses, then cut open and examined for signs of placental scars or fetuses. We also recorded their location (left or right horn) in the uterus. A fresh scar is like a black belt inside the uterine horn. After some weeks only the rims of the scar can be seen but the horn in question is still thicker at the site of the placental scar than the other horn. Some orange spots may be seen at the site of the placenta (U. Siebert pers. com.).

Due to delayed implantation, we divided the data into 'spring data' (seals killed before the implantation period, i.e. before 1 July) and 'autumn data' (seals killed after the implantation period, i.e. after 1 August). We received 472 females ( $\geq 2$ years old) from spring, mainly from May, from which we could examine the presence of placental scars. The proportion of females with placental scars from the pre-implantation sample should indicate the proportion of females that gave birth in the present year (i.e. pregnancy rate of the previous autumn). Pregnancy rate was also determined from the autumn sample as the proportion of females with fetuses after the period of implantation $(n=23)$. Because not all embryos have implanted or are so small that they cannot be seen in July, pregnancy rate was calculated from females killed after July (Bäcklin et al. 2011). Head-body length of fetuses (from nose to flipper) was also measured to calculate a

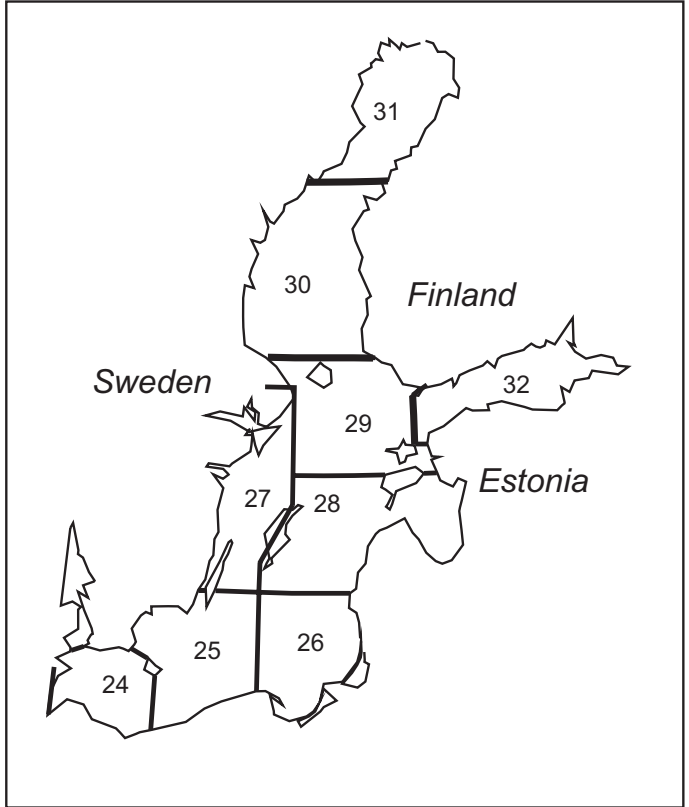

Fig. 2. Grey seal samples were collected from the Finnish sea area from ICES SD areas 29-32. Original map by Kauhala et al. (2012).

growth curve for the fetuses (sexes were pooled because the sex of most fetuses was unknown).

Ovaries were removed and cross sections (thickness about $2 \mathrm{~mm}$ ) were made with a knife. They were examined by eye for the presence of corpus luteum (CL) or corpus albicans (CA). Both sides of each section were examined for CL (yellowish, soft in texture and occasionally with a hollow center) and CA (whitish in color, scarlike in texture). The positions of CL and CA in the left or right ovary were recorded. Seals usually ovulate from alternate ovaries in successive years (Atkinson 1997, Boyd et al. 1999).

We calculated ovulation rate from the spring sample (time period between ovulation and implantation) as the proportion of females with CL ( $n=488$ for $\geq 2$-year-old females). CL remains active during the phase of delayed implantation even when a female is not pregnant but regresses in non-pregnant females after the implantation period (or if the embryo dies at an early stage) due to the absence of hormones from the placenta (Boyd 1984a, Boyd et al. 1999). Therefore, we did not use the autumn sample to calculate ovulation rate. The lengths of CL $(n=384)$ and CA $(n=$ 279) were measured to the nearest $\mathrm{mm}$. 
We also calculated the proportion of females that gave birth in the present year (i.e. were pregnant the previous autumn) from the pre-implantation sample as the proportion of females with CA ( $n=471$ for $\geq 2$-year old females). CA may persist about one year until the next parturition but may be small after the period of implantation (Hewer 1964). In non-pregnant females, CA disappears after the period of implantation because it needs progesterone and placental gonadotrophins to survive (Boyd 1984a, Boyd et al. 1999). However, as a result of the infertile estrus cycle (the present year), CA may be seen in the autumn, which can be erroneously interpreted as a sign of pregnancy in the previous year (Boyd 1984a). Pregnancy rate in the previous year on the basis of the presence of CA was thus calculated using samples only between ovulation and implantation. We tested, however, difference in pregnancy and ovulation rates between preimplantation and autumn samples to evaluate whether the autumn samples for CA and CL should indeed be excluded from our data.

To summarize, pregnancy rate was estimated using three methods. Pregnancy rate (year $t$ ): (i) the proportion of females with CA before the period of implantation (year $t+1$ ), (ii) the proportion of females with placental scars before

Table 1. Pregnancy rate of 6-24-year-old Baltic grey seal females in different years based on females with corpora albicantia (CA) and those with placental scars before the period of implantation (spring sample). Pregnancy rate was calculated when the sample size $(n)$ was at least $\sim 30$.

\begin{tabular}{lrrcrcc}
\hline Year & CA & $n$ & $\begin{array}{c}\text { Pregnancy } \\
\text { rate }\end{array}$ & Scars & $n$ & $\begin{array}{c}\text { Pregnancy } \\
\text { rate }\end{array}$ \\
\hline 2000 & 7 & 9 & - & 2 & 2 & - \\
2001 & 10 & 15 & - & 16 & 16 & - \\
2002 & 25 & 29 & 0.86 & 29 & 30 & 0.97 \\
2003 & 50 & 53 & 0.94 & 50 & 50 & 1.00 \\
2004 & 52 & 56 & 0.93 & 57 & 57 & 1.00 \\
2005 & 44 & 69 & 0.64 & 49 & 66 & 0.74 \\
2006 & 3 & 3 & - & 2 & 3 & - \\
2007 & 4 & 6 & - & 5 & 6 & - \\
2008 & 31 & 43 & 0.72 & 34 & 45 & 0.76 \\
2009 & 20 & 35 & 0.57 & 21 & 36 & 0.58 \\
2010 & 13 & 17 & - & 18 & 21 & - \\
2011 & 3 & 7 & - & 7 & 7 & - \\
Total & 263 & 343 & 0.77 & 291 & 340 & 0.86 \\
\hline
\end{tabular}

the period of implantation (year $t+1$ ), and (iii) the proportion of females with fetuses after the period of implantation (year $t$ ). Ovulation rate (year $t$ ) was calculated as the proportion of females with CL before the period of implantation (year $t$ ).

We compared pregnancy rates of females from the early and late 2000s because population growth ceased in the Finnish sea area in 2005 and the demographic structure of the population changed during the 2000s (Kauhala et al. 2012). We also calculated 'moving' pregnancy rates for 3-year periods (2000-2002, 2001-2003, 2002-2004, ..., 2009-2011) because the population growth rate changed gradually (Kauhala et al. 2012) and annual sample sizes were too small in many years (Table 1). We used only samples from spring (pregnancy rate based on CA and scars) because the autumn sample (pregnancy rate based on fetuses) was too small to compare between time periods. The spring (pre-implantation) sample consisted of females hunted between 16 April and 29 June (85\% from May) mainly (83\%) from the Bothnian Bay and the Quark (ICES SD 31 and northern part of SD 30; Kauhala \& Kunnasranta 2012), and only three adult females were by-caught in fishing gear. Therefore, there was very little spatial or temporal variation between years in the origin of the spring sample. We used Pearson's $\chi^{2}$ test or Yates' corrected $\chi^{2}$ test to compare the proportions of females with CL, CA, placental scars and fetuses in different samples.

Population numbers were estimated from annual aerial surveys during the peak moulting season in late May and early June (see Kauhala et al. 2012 for a detailed description of the method). Baltic grey seals usually breed in February-March on drift ice and exhibit some site fidelity for breeding and molting areas (Karlsson 2003, Karlsson et al. 2005). Because we used the spring sample, i.e. seals shot mainly from ice from the Finnish sea area, to compare pregnancy rates with population numbers, we also used population numbers from the Finnish sea area. However, because the entire Baltic grey seal population is considered a single population, we also compared the pregnancy rate of females in the Finnish sea area with that in the entire Baltic Sea population. It must be noted here that 
Fig. 3. Ovulation and pregnancy rates of Baltic grey seal females starting from different ages and determined from the presence of corpus luteum (CL) and corpus albicans (CA) in spring and autumn, i.e., before and after the implantation period, placental scars in spring and fetuses in autumn. * Ovulation/pregnancy rates were determined from females killed after 1 July in order to get a larger data set.

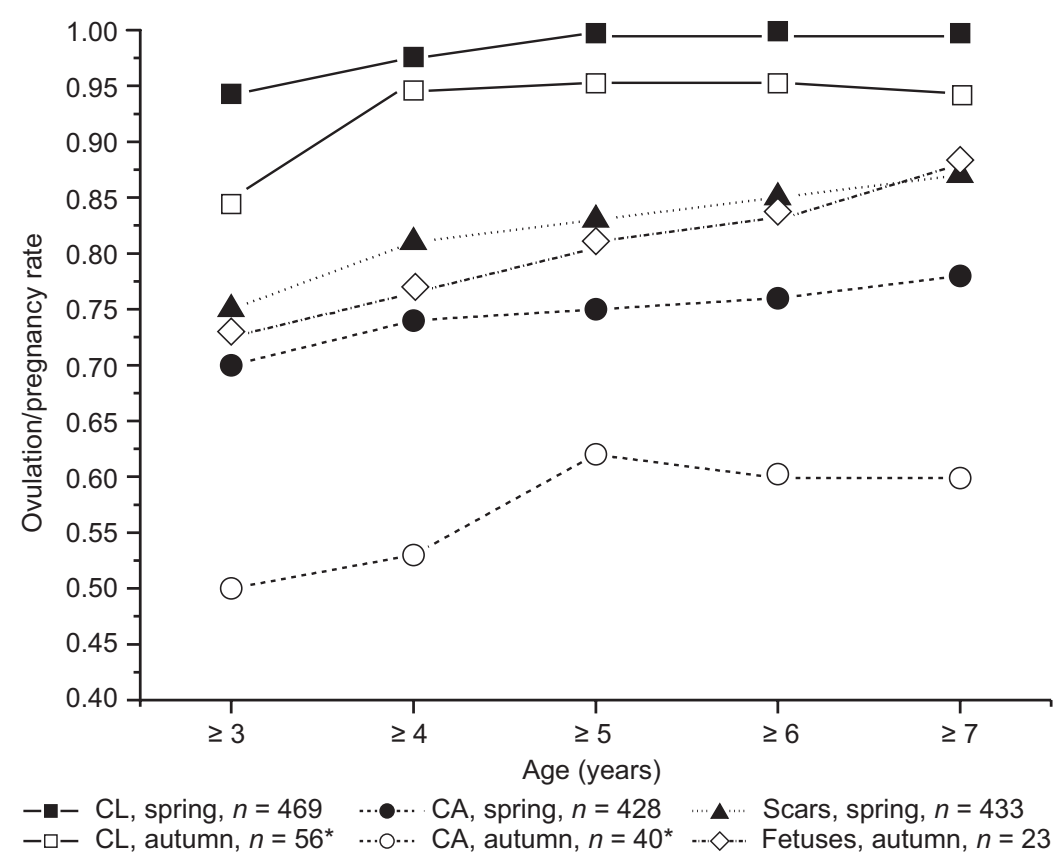

population size means the number of seals seen during aerial surveys and, e.g. weather conditions may affect the numbers. Seal numbers seen during aerial surveys should thus be treated as an index of population size. It is, however, a good estimate for the trend in population size (Harding et al. 2007), and there was no trend in the Finnish sea area after the mid-2000s (Fig. 1).

\section{Results}

\section{Comparison between methods}

Ovulation rate was significantly higher in the spring (pre-implantation) sample than in the autumn sample $\left(\chi^{2}=7.8\right.$, df $=1, p=0.005$; Fig. 3), especially when the youngest age class was included. In autumn (including data from July), CL were larger in pregnant females (mean $16.7 \mathrm{~mm} \pm \mathrm{SD} 2.41, n=19)$ than in non-pregnant females $(14.1 \mathrm{~mm} \pm 2.17, n=18$; $t$-test: $t=$ 3.4 , df $=34.9, p=0.002)$. CL of females killed in spring averaged $14.4 \mathrm{~mm} \pm 2.09(n=347)$. Furthermore, the pregnancy rate, determined on the basis of CA, was higher in the spring sample $\left(\chi^{2}=13.3, \mathrm{df}=1, p<0.001\right)$. CA were larger in spring $(8.5 \mathrm{~mm} \pm 1.64, n=251)$ than in autumn
(7.1 $\mathrm{mm} \pm 2.25, n=18 ; t$-test: $t=2.6, \mathrm{df}=18.3$, $p=0.019)$. Because of significant differences between spring and autumn samples, with low numbers in the autumn dataset, we only used data from spring hereafter when comparing ovulation and pregnancy rates between age classes or time periods.

The pregnancy rate based on placental scars in spring tended to get higher values than that based on $\mathrm{CA}\left(\chi^{2}=3.7, \mathrm{df}=1, p=0.054, n=406\right.$ females with information of both CA and scars). However, the pregnancy rate derived from placental scars/CA in spring did not differ significantly from that derived from fetuses in autumn (scars: $\chi^{2}=0.12$, df $=1, p=0.725$; CA: $\chi^{2}=$ $0.08, \mathrm{df}=1, p=0.778)$. In $94 \%$ of the females which had both CA and placental scars ( $n=$ 263) they were on the same side (right/left ovary and uterine horn). In $6 \%$ of the cases, CA and scars were either on opposite sides or there were signs of scars in both uterine horns. All of these females were $\geq 8$ years old, and $82 \%$ were $\geq 10$ years old.

In July, 4 out of 8 females determined as pregnant had only very small embryos, which were not measured. The head-body length of the fetus increased rapidly and linearly from late August onwards (Fig. 4). 


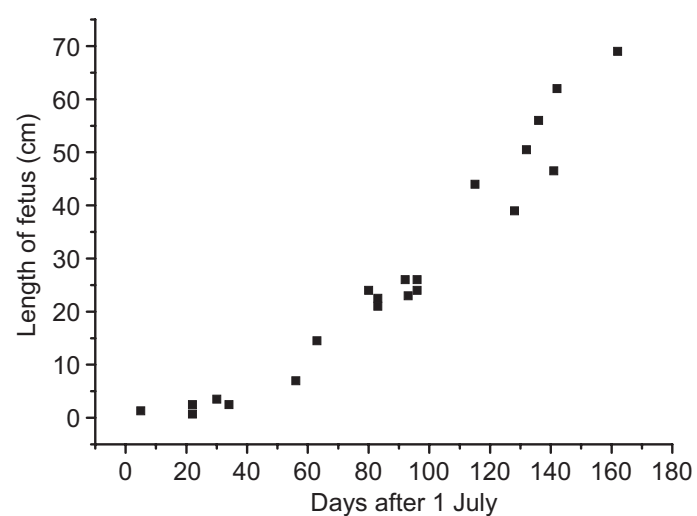

Fig. 4. The head-body length (from nose to flipper) of Baltic grey seal fetuses $(n=17)$, determined after 1 July in 2000-2012. From day 56 onwards: Length of fetus $=0.56 \times$ days after 1 July $-25.1\left(r^{2}=0.94, F=\right.$ 206, $\mathrm{df}=1,14, p<0.001)$.

\section{Ovulation and pregnancy rates at different ages}

The ovulation rate calculated using collective data was 0.94 (469 females that were $>2$ years old), whereas that of $\geq 5$-year-old females was 0.99 ( $n=409$; Figs. 3 and 5). The pregnancy rate of the 6-24-year-old females, i.e. females in the best reproductive age according to Bowen et al. (2006), was as high as 0.77-0.86, depending on the method used, and the lowest in the 4-5-year-old females (0.54-0.56; Table 2). However, in our data the pregnancy rate of 7-11-year-old females was the highest: it was 0.86 according to both CA and scars. The proportion of females with $\mathrm{CA} / \mathrm{scars}$ increased to the age of 9-10 years and gradually declined thereafter (Fig. 5). The oldest female with CA and placental scars in our data was a $~ 40$-year old female. We found one case with uterine occlusion (in only one uterine horn): a 13-yearold female killed in 2009.

\section{Pregnancy rate in different time periods}

The pregnancy rate of all females ( $\geq 4$ years old, determined from CA) differed between years $\left(\chi^{2}=28.4\right.$, df $=13, p=0.008$; Table 1$)$. The pregnancy rate determined from $\mathrm{CA}$ or from placental scars was higher in 2000-2004 than in 2005-2011 (Table 3). However, among 4-5-year-old females, the pregnancy rate from CA did not differ significantly between the time periods (but sample sizes were small), although based on placental scars it tended to be lower during the latter period. Among 6-24-year-old females, the pregnancy rate derived from CA was as high as 0.89 in 2000-2004, but only 0.66

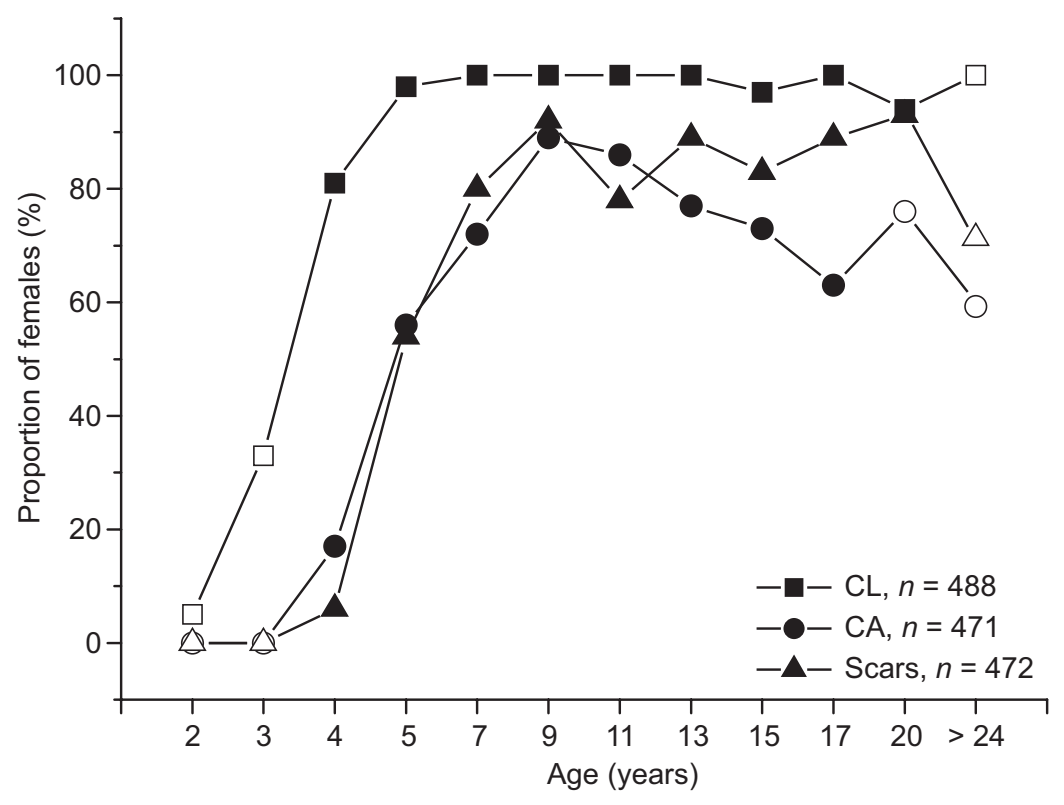

Fig. 5. The proportions of Baltic grey seal females of different ages with corpora lutea (CL), corpora albicantia (CA) and sings placental scars in the spring samples (the preimplantation period) from 2000-2012. Two-year age groups were used for $\geq 5$-year-old females to get larger data sets for each age group, i.e., age $5=$ 5-6-year-old females, etc., except in older age classes where data for several age classes were pooled (17 =17-19, 20 = 20-24). Points with sample sizes $<30$ are marked with open symbols. Note that the pregnancy rate at age $t=$ the proportion of females with $\mathrm{CA} /$ scars at age $t+1$. 
Table 2. Pregnancy rates of Baltic grey seal females of different age classes based on the number of females with corpora albicantia (CA) and those with placental scars in spring (before the implantation period), and the number of females with fetuses in autumn (after the implantation period) in 2000-2011. Pregnancy rate was calculated when the sample size $(n)$ was at least 30 .

\begin{tabular}{lrrrrrrrrr}
\hline Age (years) & CA & $n$ & $\begin{array}{c}\text { Pregnancy } \\
\text { rate }\end{array}$ & Scars & $n$ & $\begin{array}{c}\text { Pregnancy } \\
\text { rate }\end{array}$ & Fetus & $\begin{array}{c}n \\
\text { Pregnancy } \\
\text { rate }\end{array}$ \\
\hline$\geq 4$ & 294 & 398 & 0.74 & 324 & 398 & 0.81 & 17 & 22 & - \\
$4-5$ & 25 & 45 & 0.56 & 26 & 48 & 0.54 & 1 & 3 & - \\
$6-24$ & 263 & 343 & 0.77 & 291 & 340 & 0.86 & 16 & 19 & - \\
$7-11$ & 122 & 142 & 0.86 & 121 & 141 & 0.86 & 6 & 7 & - \\
$>24$ & 6 & 10 & - & 7 & 10 & - & - & - & - \\
\hline
\end{tabular}

thereafter. The pregnancy rate of 6-24-year-old females differed, however, also between areas during the latter period (2005-2011). It was 0.62 $(n=141)$ in the Bothnian Bay and $0.81(n=39)$ in the other areas $\left(\chi^{2}=4.3, \mathrm{df}=1, p=0.039\right)$. There was no difference between areas in 20002004. The decline in the pregnancy rate was thus sharper in the northernmost area, the Bothnian Bay, than in more southern areas.

The 'moving' pregnancy rate showed a declining trend (CA: $r=-0.85, p=0.002$, scars: $r=-0.94, p<0.001$; Fig. 6). The decreasing trend in pregnancy rate could be seen in both age groups (4-5-year-old and 6-24-yearold females), and the decline was sharper in the younger age group (but small sample size). The pregnancy rate of 6-24-year-old females correlated negatively with population size in the Finnish sea area (CA: $r=-0.66, p=0.039$; scars: $r=-0.84, p=0.002$ ) and with seal numbers in the whole Baltic Sea (CA: $r=-0.78, p=0.008$; scars: $r=-0.94, p<0.001)$.

\section{Discussion}

\section{Differences between the methods}

Some differences between the results obtained with different methods existed. The pregnancy rate based on corpus albicans (CA) was higher according to the pre-implantation sample than according to the autumn sample, which points to the conclusion that some CA have indeed disappeared after the period of implantation as Boyd (1984a) reported. Therefore, only the samples of seal females killed before the implantation period should be included when estimating pregnancy rate of the previous year from CA.

The pregnancy rate derived from placental scars (before implantation) tended to be higher (up to $99 \%$ ) than that based on CA. In cases when CA and the placental scar were on opposite sides (usually they are on the same side, Atkinson 1997) or when there were signs of scars in both uterine horns, mainly concerned older females. In multiparous females, one can sometimes see signs of placental scars from earlier years (Ouellette \& Ronald 1985), which may

Table 3. Pregnancy rates of Baltic grey seal females of different age classes for two time periods, 20002004 and 2005-2011, determined from the presence of corpus albicans (CA) and placental scars before the period of implantation (spring sample). Sample sizes are given in parentheses. Differences between the two time periods were tested with the $\chi^{2}$-test, and the values for $\chi^{2}$ and $p$ are given ( $\mathrm{df}=1$ for all tests). Sample sizes for 4-5-year-old females were small $(<30)$.

\begin{tabular}{llll}
\hline Period/Method & $\begin{array}{c}\text { Age } \\
\text { (years) }\end{array}$ & \multicolumn{1}{c}{ CA } & \multicolumn{1}{c}{ Scars } \\
\hline $2000-2004$ & $\geq 4$ & $0.86(183)$ & $0.96(176)$ \\
$2005-2011$ & $\geq 4$ & $0.64(215)$ & $0.70(221)$ \\
& $\chi^{2}, p$ & $24.3,<0.001$ & $32.6,<0.001$ \\
$2000-2004$ & $4-5$ & $0.63(19)$ & $0.70(20)$ \\
$2005-2011$ & $4-5$ & $0.48(25)$ & $0.25(28)$ \\
& $\chi^{2}, p$ & $0.74,0.388$ & $3.46,0.063$ \\
$2000-2004$ & $6-24$ & $0.89(162)$ & $0.99(155)$ \\
$2005-2011$ & $6-24$ & $0.66(180)$ & $0.74(184)$ \\
& $\chi^{2}, p$ & $25.9,<0.001$ & $44.3,<0.001$ \\
$2000-2004$ & $7-11$ & $0.94(67)$ & $1.00(65)$ \\
$2005-2011$ & $7-11$ & $0.78(74)$ & $0.74(76)$ \\
& $\chi^{2}, p$ & $7.3,0.007$ & $17.8,<0.001$ \\
\hline
\end{tabular}




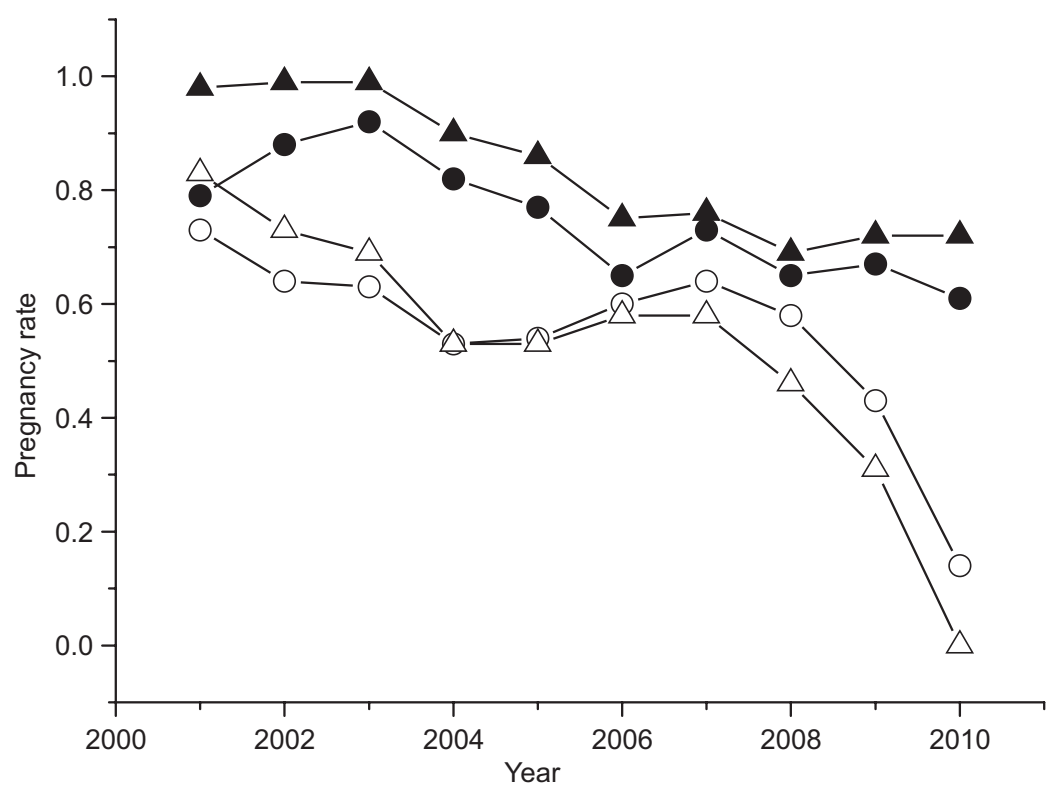

- - CA, 6-24-year old, $n=342 \quad$-O- CA, 4-5-year old, $n=44$

-A-Scars, 6-24-year old, $n=339 \quad-\triangle-$ Scars, 4-5-year old, $n=48$
Fig. 6. Pregnancy rates of 4-5-year-old and 6-24-year-old females, determined from the presence of corpus albicans (CA) and placental scars in seal females killed before the period of implantation in spring in the Finnish sea area during different time periods (2000-2002, 20012003 ... 2009-2011, i.e., the data were smoothed with three-year moving averages). Sample size for each point varied between 48 and 178 for 6-24-year old females. Sample sizes were small (5-16) for 4-5-year-old females. result in overestimates of the pregnancy rate. However, pregnancy rate on the basis of placental scars/CA in spring and that based on fetuses in autumn did not differ significantly. Therefore, our estimates of pregnancy rates, based on several methods, should be fairly reliable. Also Boyd (1985) found that pregnancy rates derived from CA and fetuses were similar in grey seals.

Ovulation rate, especially that for younger age classes, was higher when calculated from the pre-implantation sample than from the autumn sample (Fig. 3), because CL may disappear after the implantation period if the female fails to become pregnant (Boyd 1984a). Ovulation rate should thus be calculated from the pre-implantation sample. Furthermore, if pregnancy rate is calculated from CL after implantation, the size of CL should be measured, and only large CLs (larger than about $16.5 \mathrm{~mm}$ ) should be interpreted as indicators of pregnancy, because in non-pregnant females, CL are much smaller (if they persist) than those in pregnant females (Boyd 1984a). Using autumn CL (during pregnancy) may also lead to overestimation of the true birth rate due to fetal mortality: the pregnancy rate determined from fetuses was 0.875 and that from CL was 1.0 in the northwest Atlantic population (Hammill \& Gosselin 1995).

\section{Ovulation and pregnancy rates at different ages}

Uterine occlusions, most probably caused by environmental pollutants, are a unique feature for Baltic seals, especially for the ringed seal (Phoca hispida botnica; e.g., Helle et al. 1976, Bergman 1999). Only one case with uterine occlusion was found in the present study, and no cases existed in Swedish grey seal data from the Gulf of Bothnia in 2002-2007 (Bäcklin et al. 2011). Reproductive health of Baltic grey seal females can therefore be considered normal today. Reproductive health of the ringed seal has also increased in recent years (Bäcklin et al. 2013a).

The ovulation rate was 0.33 in 3 -year-old females (calculated from a small sample size), 0.81 in 4-year-old females and increased thereafter, being almost 1.0 after the age of five years. These results were in concordance with some earlier studies: the age of sexual maturity in grey seals is 3-5 years (Atkinson 1997), the ovulation rate of the 4-year-old females on the Herbides and Farne Islands was 0.80 (Boyd 1985) and the ovulation rate of grey seals aged five years and older approached $100 \%$, e.g., on Sable Island, Canada (Bowen et al. 2006). The average age of 
sexual maturity for grey seal females was four years in a low-density population of Iceland (Hauksson 2007). In the Atlantic stocks, the mean age at first parturition was 5.2-5.5 years but occasionally females gave birth at the age of three years (Hammill \& Gosselin 1995, Schwarz \& Stobo 2000).

In the present study, the pregnancy rate of all females $\geq 4$-years-old was $0.74-0.81$, which is close to the values given in earlier studies from the Baltic Sea (0.75-0.87; Harding et al. 2007, Bäckling et al.2013a) and within limits given in Atlantic studies (0.66-0.94; Bowen et al. 2003, Harwood \& Prime 1978). Boyd et al. (1999) estimated that pregnancy rates between 0.5 and 0.9 are normal for pinnipeds and they suggested that the pregnancy rate varies according to population density and food availability.

The lower pregnancy rate of the youngest females (4-5 years old) in the present study has also been shown in earlier studies (e.g., Boyd 1985, Schwarz \& Stobo 2000, Bowen et al. 2006, Hauksson 2007, Bäcklin et al. 2013a). The pregnancy rate for adult females (6-24-year-old females: $0.77-0.86$ ) in the present study for the whole study period was somewhat lower than the values given for some rapidly increasing populations: the pregnancy rate was as high as 0.955 during population increase in the Baltic Sea (Bäcklin et al. 2013a) and 0.88-0.97 in rapidly increasing Atlantic stocks (e.g. Boyd 1985, Hammill \& Gosselin 1995, Hauksson 2007).

The pregnancy rate of grey seals decreases after the age of 24 years (Bowen et al. 2006, present study). Reproductive senescence is thus not evident in grey seals before the age of 25 . However, even females over 40 years old can still be reproductively active (Bowen et al.2006, present study). Probable reasons for senescence are reduced ovarian function, reduced transfer of nutrients to the fetus or reduced functionality of the placenta (Bowen et al. 2006). Producing offspring reduces the probability of survival and future reproductive success, i.e., there are costs of reproduction (e.g. Clutton-Brock et al. 1982, Stearns 1992). Old females thus tend to have lower pregnancy rates. The reproductive value of Baltic grey seals decreased after the age of five years (Kauhala et al. 2012).

\section{Declining pregnancy rate during the 2000s}

The pregnancy rate for 6-24-year-old females (from CA) was 0.89 during the early 2000s and declined thereafter being only 0.66 in the late 2000s. Our prediction of the decline in pregnancy rate at high population density was thus verified. Pregnancy rate from the early 2000s was close to values obtained in the rapidly increasing populations in the North Atlantic (e.g., Boyd 1985, Hammill \& Gosselin 1995) and in the Baltic Sea (Bäcklin et al. 2013a), and it was similar in the Bothnian Bay and in the more southern areas. However, pregnancy rate in the latter time period, when population growth ceased in the Finnish sea area and also in Estonia (I. Jüssi pers. comm.), was lower, and it was lower in the Bothnian Bay than in the other Finnish sea areas. It was, however, within the limits of 'normal' pregnancy rate (Boyd et al. 1999). The decline in pregnancy rate, especially in the northernmost area, may point to the conclusion that grey seal numbers are close to the carrying capacity of the northern parts of the Baltic Sea.

The negative correlation between pregnancy rate and population size in the present study may thus be due to density-dependent processes acting on the population (e.g. Ricklefs 1973, Sinclair \& Norton-Griffiths 1979, Begon et al. 1986, Flowerdew 1987). In long-lived K-strategist species, such as the grey seal, reduced fecundity is an important density-dependent factor acting on high densities (e.g., Clutton-Brock et al. 1982, Begon et al. 1986). Also, the survival rate of Baltic grey seal females, especially those $<10$ years old, declined when population size increased (Kauhala et al. 2012). The fitness of an average individual is supposed to decline as a function of population density, and population size may thus affect reproductive parameters and also survival rates in seals (Hammill \& Gosselin 1995, Bowen et al. 2006, Svensson et al. 2011). In Iceland, a high reproductive rate in a lowdensity grey seal population indeed suggests a density-dependent response to population numbers (Hauksson 2007).

Body condition may affect pregnancy rate, because it plays an important role in both implantation and maintenance of pregnancy in mam- 
mals (Boyd 1984b, Bowen et al. 2006). Body condition (blubber thickness) of Baltic grey seals, especially in younger age classes, has indeed decreased during the 2000s (Bäcklin et al. $2013 b)$. If population numbers are high in relation to food resources, individuals may have thinner fat reserves, which may, in turn, affect their pregnancy rate (e.g., Clutton-Brock et al. 1982, Atkinson 1997). In a rapidly increasing population, i.e., in a population which is below the environmental carrying capacity, females probably have larger fat reserves and reproduce at a younger age than in a high-density population (Atkinson 1997, Bowen et al. 2006, 2007, Svensson et al. 2011). In the present study, the pregnancy rate of the youngest females indeed declined more in the late 2000s than that of older females. Also, the survival rate of young seals is likely affected by their body condition and therefore may decrease when population density increases (Svensson et al. 2011). The increased mortality rate of young grey seal females found in the earlier study may, however, also be due to their increased proportion in the hunting catch and/or among by-caught seals (Kauhala \& Kunnasranta 2012, Kauhala et al. 2012). The true number and demographic structure of by-caught seals in the Baltic Sea is unknown. It cannot, however, be ruled out that density-dependent factors also affect the population, especially in northern areas, and cause a higher mortality rate of young seals and a lower pregnancy rate of females.

\section{Conclusions}

Results of the present study point to the conclusion that density-dependent factors may affect the part of the Baltic grey seal population that mainly breeds and moults in the Finnish sea area. The population growth has ceased, pregnancy rate has declined and mortality rate of young females has increased in recent years. It is not, however, clear what is the carrying capacity of the Baltic Sea for grey seals today, and what are the resources (if any) regulating population size. There probably were even 100000 Baltic grey seals in the early 20th century (e.g., Harding et al. 2007), but the carrying capacity may change over time (Svensson et al. 2011).
Other explanations, beside those based on density-dependent factors, to the decreased pregnancy rate during the latter half of the 2000s must also be considered. During mild winters when there is only little ice, many Baltic grey seal pups are born on land and their average body weights at weaning are lower than those born during colder winters on ice (Jüssi et al. 2008). Weather (ice) conditions in winter may thus affect the pregnancy rate of females later in life, because early growth and subsequent reproductive success are often linked in mammals, at least in males (Clutton-Brock et al. 1982). Climate and ice conditions probably also affected reproductive parameters of ringed seals (Chambellant et al. 2012). The impact of climate change on Baltic seal populations should be investigated.

The breeding success of males has not been taken into account in the present study. It is unknown whether the breeding success of males has changed, and how it might affect the pregnancy rate of females. The proportion of males in the population increased during the 2000s (Kauhala et al. 2012), which may have an effect on their reproductive success. Further research on this subject is needed.

\section{Acknowledgements}

We wish to thank the anonymous reviewers for their good comments. We are most grateful to B.-M. Bäcklin, E. Helle, A. Herrero, M. Isomursu, C. Moraeus, P. Timonen and M. Valtonen, who examined the uteri and ovaries of the seals, and T. Alapassi who did age determination slides for us. We also want to thank all of the hunters who sent seal samples to us.

\section{References}

Ahola, M. 2014: Merihylkeet vuonna 2011-2012. - In: Wikman, M. (ed.), Riistakannat 2011-2012, Riista- ja kalatalous - Tutkimuksia ja selvityksiä, Riista- ja kalatalouden tutkimuslaitos. [In press].

Almkvist, L. 1978: Seal stock sizes along the Swedish coasts in 1976. - Finnish Game Research 37: 22-24.

Atkinson, S. 1997: Reproductive biology of seals. - Reviews of Reproduction 2: 175-194.

Begon, M., Harper, J. L. \& Townsend, C. L. 1986: Ecology. Individuals, population and communities. - Blackwell Scientific Publications, Oxford, UK. 
Bergman, A. 1999: Health condition of the Baltic grey seal (Halichoerus grypus) during two decades: gynaecological health improvement but increased prevalence of colonic ulcers. - Acta Pathologica Microbiologica et Immunologica Scandinavica 107: 270-282.

Bergman, A. \& Olsson, M. 1986: Pathology of Baltic grey seal and ringed seal females with special reference to adrenocortical hyperplasia: Is environmental pollution the cause of a widely distributed disease syndrome? Finnish Game Research 44: 47-62.

Bowen, W. D., McMillan, J. I. \& Mohn, R. 2003: Sustained exponential population growth of grey seals at Sable Island, Nova Scotia. - ICES Journal of Marine Science 60: $1265-1274$.

Bowen, W. D., Iverson, S. J., McMillan, J. I. \& Boness, D. J. 2006: Reproductive performance in grey seals: agerelated improvement and senescence in a capital breeder. - Journal of Animal Ecology 75: 1340-1351.

Bowen, W. D., McMillan, J. I. \& Blanchard, W. 2007: Reduced population growth of gray seals at Sable Island: evidence from pup production and age of primiparity. Marine Mammal Science 23: 48-64.

Boyd, I. L. 1983: Luteal regression, follicle growth and the concentration of some plasma streroids during lactation in grey seals (Halichoerus grypus). - Reproduction, the Journal of the Society for Reproduction and Fertility 69: $157-164$.

Boyd, I. L. 1984a: Development and regression of the corpus luteum in grey seal (Halichoerus grypus) ovaries and its use in determining fertility rates. - Canadian Journal of Zoology 62: 1095-1100.

Boyd, I. L. 1984b: The relationship between body condition and the timing of implantation in pregnant Grey seals (Halichoerus grypus). - Journal of Zoology 203: 113-123.

Boyd, I. L. 1985: Pregnancy and ovulation rates in Grey seals (Halichoerus grypus) on the British coast. - Journal of Zoology 205: 265-272.

Boyd, I. L., Lockyer, C. \& Marsh, H. D. 1999: Reproduction in marine mammals. - In: Reynolds, J. E. \& Rommel, S. A. (eds.), Biology of marine mammals: 218-286. Smithsonian Institution Press, Washington.

Bäcklin, B., Eriksson, L. \& Olovsson, M. 2003: Histology of uterine leiomyoma and occurrence in relation to reproductive activity in the Baltic grey seal (Halichoerus grypus). - Veterinary Pathology 40: 175-180.

Bäcklin, B.-M., Moraeus, C., Roos, A., Eklöf, E. \& Lind, Y. 2011: Health and age and sex distributions of Baltic grey seals (Halichoerus grypus) collected from bycatch and hunt in the Gulf of Bothnia. - ICES Journal of Marine Science 68: 183-188.

Bäcklin, B.-M., Moraeus, C., Kauhala, K. \& Isomursu, M. of Ad hoc HELCOM SEAL Expert Group 2013a: Pregnancy rates of the marine mammals - Particular emphasis on Baltic grey and ringed seals. - HELCOM Core Indicator Report, available at http://www.helcom. fi/Core\%20Indicators/HELCOM-CoreIndicator-Pregnancy_rates_of_marine_mammals.pdf.

Bäcklin, B.-M., Moraeus, C., Kauhala, K. \& Isomursu, M. of Ad hoc HELCOM SEAL Expert Group 2013b:
Nutritional status of seals. - HELCOM Core Indicator Report, available at http://www.helcom.fi/Core $\% 20$ Indicators/HELCOM-CoreIndicator-Nutritional_status_ of_seals.pdf.

Chambellant, M., Stirling, I., Gough, W. A. \& Ferguson, S. H. 2012: Temporal variations in Hudson Bay ringed seal (Phoca hispida) life-history parameters in relation to environment. - Journal of Mammalogy: 93: 267-281.

Clutton-Brock, T. H., Guinness, F. E. \& Albon, S. D. 1982: Red deer: behavior and ecology of two sexes. - The University of Chicago Edinburgh University Press, Edinburgh.

Flowerdew, J. R. 1987: Mammals, their reproductive biology and population ecology. - Edward Arnold publishers Ltd., London.

Hammill, M. O. \& Gosselin, J. F. 1995: Grey seal (Halichoerus grypus) from the Northwest Atlantic: female reproductive rates, age at first birth, and age of maturity in males. - Canadian Journal of Fisheries and Aquatic Sciences 52: 2757-2761.

Harding, K. C. \& Härkönen, T. 1999: Development in the grey seal (Haliochoerus grypus) and ringed seal (Phoca hispida) populations during the 20th century. - Ambio 28: 619-627.

Harding, K.C., Härkönen, T., Helander, B. \& Karlsson, O. 2007: Status of Baltic grey seals: Population assessment and extinction risk. - NAMMCO Sci. Publ. 6: 33-56.

Harwood, J. \& Prime, J. H. 1978: Some factors affecting the size of British grey seal populations. - Journal of Applied Ecology 15: 401-411.

Hauksson, E. 2007: Growth and reproduction in the Icelandic grey seal. - In: Haug, T., Hamill, M. \& Ólafsdóttir, D. (eds.), Grey seals in the North Atlantic and the Baltic: 153-162. The North Atlantic Marine Mammal Commission, Troms $\emptyset$.

Helle, E., Olsson, M. \& Jensen, S. 1976: PCB levels correlated with pathological changes in seal uteri. - Ambio 5: 261-263.

Hewer, H. R. 1964: The determination of age, sexual maturity, longevity and a life-table in the grey seal (Halichoerus grypus). - Proceedings of the Zoological Society of London 142: 593-630.

Jensen, S., Johnels, A. G., Olsson, M. \& Otterlind, G. 1969: DDT and PCB in marine mammals from Sweden. Nature 224: 247-250.

Jüssi, M., Härkönen, T., Helle, E. \& Jüssi, I. 2008: Decreasing ice coverage will reduce the breeding success of Baltic grey seal (Halichoerus grypus) females. - Ambio 37: $80-85$.

Karlsson, O. 2003: Population structure, movements and site fidelity of grey seals in the Baltic Sea. - Ph.D. thesis, Department of Zoology, Stockholm University.

Karlsson, O., Hiby, L., Lundberg, T., Jüssi, M., Jüssi, I. \& Helander, B. 2005: Photo-identification, site fidelity, and movement of female gray seals (Halichoerus grypus) between haul-outs in the Baltic Sea. - Ambio: 34: 628-634.

Kauhala, K. \& Kunnasranta, M. 2012: Size and structure of grey seal hunting bag in Finland. - Suomen Riista 58: 7-15. [In Finnish with English summary]. 
Kauhala, K., Ahola, M. P. \& Kunnasranta, M. 2012: Demographic structure and mortality rate of a Baltic grey seal population at different stages of population change, judged on the basis of the hunting bag in Finland. Annales Zoolgici Fennici 49: 287-305.

Kokko, H., Lindström, J. \& Ranta, E. 1997: Risk analysis of hunting of seal populations in the Baltic. - Conservation Biology 11: 917-927.

Mansfield, A. W. 1991: Accuracy of age determination in the grey seal Halichoerus grypus of eastern Canada. Marine Mammal Science 7: 44-49.

Nyman, M., Bergknut, M., Fant, M. L., Raunio, H., Jestoi, M., Bengs, C., Murk, A., Koistinen, J., Bäckman, C., Pelkonen, O., Tysklind, M., Hirvi, T. \& Helle, E. 2003: Contaminant exposure and effects in Baltic ringed and grey seals as assessed by biomarkers. - Marine Environmental Research 55: 73-99.

Ouellette, J. \& Ronald, K. 1985: Histology of reproduction in harp and grey seals during pregnancy, postparturition, and estrus. - Canadian Journal of Zoology 63: 1778-1796.

Ricklefs, R. E. 1973: Ecology. - Thomas Nelson and Sons Ltd., Middlesex, UK.
Roos, A. M., Bäcklin, B.-M., Helander, B. O., Rigét, F. F. \& Eriksson, U. C. 2012: Improved reproductive success in otters (Lutra lutra), grey seals (Halichoerus grypus) and sea eagles (Haliaeetus albicilla) from Sweden in relation to concentrations of organochlorine contaminants. Environmental Pollution 170: 268-275.

Routti, H. 2009: Biotransformation and endocrine disruptive effects of contaminants in ringed seals - implications for monitoring and risk assessment. - Annales Universitatis Turkuensis, Ser. AII, Tom. 243: 1-48.

Schwarz, C. J. \& Stobo, W. T. 2000: Estimation of juvenile survival, adult survival, and age-specific pupping probabilities for the female grey seal (Halichoerus grypus) on Sable Island from capture-recapture data. - Canadian Journal of Fisheries and Aquatic Sciences 57: 247-253.

Sinclair, A. R. E. \& Norton-Griffiths, M. 1979: Serengeti. Dynamics of an Ecosystem. - The University of Chicago Press, Chicago.

Stearns, S. C. 1992: The Evolution of life histories. Oxford University Press, Oxford.

Svenson, C. J., Eriksson, A., Harkonen, T. \& Harding, K. C. 2011: Detecting density dependence in recovering seal populations. - Ambio 40: 52-59. 